Eur. J. Clin. Chem. Clin. Biochem.

Vol. 31, 1993, pp. 591-594

(C) 1993 Walter de Gruyter \& Co.

Berlin · New York

\title{
A New Approach for the Rapid Detection of Common and Atypical Aldehyde Dehydrogenase Alleles
}

\author{
By Guang-chou Tu ${ }^{1}$ and Yedy Israel ${ }^{1,2}$ \\ ${ }^{1}$ Addiction Research Foundation of Ontario, Toronto, Ontario, Canada \\ ${ }^{2}$ Departments of Pharmacology and Medicine, University of Toronto, Toronto, Ontario, Canada
}

(Received February 3/May 27, 1993)

Summary: A strong protection against the development of alcoholism is exerted by a point mutation in the gene coding for low $K_{\mathrm{m}}$ aldehyde dehydrogenase (ALDH), i. e. $\mathrm{ALDH}_{2}$. We report a non-radioactive method for determining the common and atypical human mitochondrial aldehyde dehydrogenase $\left(\mathrm{ALDH}_{2}\right)$ genotypes. This method is based on the fact that the base change $(\mathrm{G} \rightarrow \mathrm{A})$ in Exon 12 of the $\mathrm{ALDH}_{2}$ gene abolishes an Eco57 I restriction site (CTGAAG $\rightarrow$ CTAAAG). A GC-clamp attached oligonucleotide was designed to yield a 176 base pair product by the polymerase chain reaction. After amplification, the resulting fragment containing the normal nucleotide sequence is cut by Eco57 I into two segments (131 base pairs +45 base pairs) while the fragment containing the mutated sequence remains intact (176 base pairs). These are visualized by staining with ethidium bromide on agarose gels without blotting, hybridization or autoradiography.

\section{Introduction}

A single base substitution (G/A) in Exon 12 of mitochondrial aldehyde dehydrogenase $\left.\left(\mathrm{ALDH}_{2}\right)^{1}\right)$ gene causes the loss of the activity of the enzyme coded (1). Individuals carrying this gene mutation are unable to rapidly detoxify acetaldehyde produced in the metabolism of ethanol. When alcohol is consumed by these individuals, blood acetaldehyde concentrations are markedly increased, reaching values which lead to the development of facial flushing, hypotension, tachycardia, nausea and in some cases vomiting $(2,3)$.

Racial differences in $\mathrm{ALDH}_{2}$ alleles between Caucasians and Orientals have been found. Approximately $30-50 \%$ of Orientals have the mutant gene, while virtually all Caucasians examined thus far have the usual alleles $(4,5)$.

The existence of the $\mathrm{ALDH}_{2}$ gene mutation has been shown to drastically lower the prevalence of alcohol

\footnotetext{
1) Enzymes: Aldehyde dehydrogenase (aldehyde : NAD ${ }^{+}$oxidoreductase, EC 1.2.1.3)

Eco 57 I (restriction endonuclease, EC 00.00.00.0)
}

dependence. In Japan, only 5\% of alcohol dependent patients present the mutation compared with about $40 \%$ for the normal population (6). Thus, the mutation exerts an $80-90 \%$ reduction in the risk of becoming an alcoholic. In Taiwan, the protection is of the order of $75 \%$ (7).

In order to elucidate the possible association between $\mathrm{ALDH}_{2}$ genotypes, alcohol sensitivity, alcoholism, and other alcohol-related morbidities, it is important to develop a simple and reliable genotyping method.

In 1987, Hsu et al. (8) first developed a method for determining human $\mathrm{ALDH}_{2}$ genotypes. These investigators used two 21-base synthetic oligonucleotides, one complementary to the usual $\mathrm{ALDH}_{2}$ gene and the other complementary to the atypical $\mathrm{ALDH}_{2}$ gene, as specific probes for in-gel hybridization analysis of human genomic DNA. Under appropriate hybridization conditions, these two probes hybridize to their specific complementary alleles and thus allow the genotyping of the $\mathrm{ALDH}_{2}$ locus.

In 1989, Crabb et al. (9) developed a method for $\mathrm{ALDH}_{2}$ genotyping based on the amplification of 
genomic DNA by the polymerase chain reaction (PCR). This method is faster and requires smaller amounts of DNA ( $2 \mu \mathrm{g}$ or less) than methods that use probing of Southern blots of genomic DNA digested with restriction endonuclease. Singh et al. (5) and Enomoto et al. (10) improved the method by employing the dot-blot and slot-blot hybridization.

The above methods are time-consuming and require the use of radioactive phosphorous $\left({ }^{32} \mathrm{P}\right)$. We have developed a simple non-radioactive method in which the gene fragment containing either the mutated or the normal sequence is amplified by the PCR reaction and is then cut by a new restriction enzyme $\left.(E \operatorname{co5} 7 \mathrm{I})^{1}\right)$ that recognizes only the normal (CTGAAG), but not the mutated (CT $A A A G$ ) nucleotide sequence. Following enzymatic digestion, separation by electrophoresis and staining by ethidium bromide, two distinct bands from the fragment containing the normal sequence, can be seen on agarose gels. The mutated sequence, not recognized by Eco57 I, yields only one band.

\section{Materials and Methods}

Whole blood and hair root samples

Samples of whole blood and hair roots were collected from 12 individuals working at the University of Toronto. The volunteer number is indicated by the number or the subscript in figures 2-4. [Chinese (\#1-5, \#8-9), Caucasians (\#6, \#12), Chileans (\#7, \#11), Indian (\#10)].

\section{Genomic DNA}

Genomic DNAs were prepared from either $50 \mu \mathrm{l}$ of whole blood or 10 hair roots as described in a previous paper (11). The samples were dissolved in $20 \mu \mathrm{l}$ of buffer $(10 \mathrm{mmol} / \mathrm{l}$ Tris$\mathrm{HCl}, \mathrm{pH} 8.0$ and $1 \mathrm{mmol} / \mathrm{l}$ EDTA).

\section{Oligonucleotides}

Two polymerase chain reaction (PCR) primers and two $\mathrm{ALDH}_{2}$ allele-specific probes were synthesized on an Applied Biosystems 380B DNA synthesizer. The base sequences of two $\mathrm{ALDH}_{2}$ allele-specific ${ }^{32} \mathrm{P}$-probes are the same as these used by $\mathrm{Hsu}$ et al. (8), Crabb et al. (9) and $O^{\prime}$ Dowd et al. (11). The base sequence of PCR primer \#1 (23 mer) and primer \#2 (60 mer) are: $5^{\prime}$ CAAATTACAGGGTCAACTGCTAT- $3^{\prime}$ and 5'-CCGCGCC CGCCGCCCCGCGCCCCCCCGCCCGCCCCGCGCTCCAC ACTCACAGTTTTCAC-3', respectively.

\section{Polymerase chain reaction}

A $10 \mu \mathrm{l}$ aliquot of the genomic DNA, extracted from either whole blood or hair roots as indicated above, was mixed with 100 pmol of each primer and submitted to the polymerase chain reaction using GeneAmp PCR Reagent kit with Ampli Taq DNA Polymerase (Perkin-Elmer Cetus). The amplification temperature conditions were as follows: $94^{\circ} \mathrm{C}$ for $5 \mathrm{~min}$ followed by 30 cycles consisting of $1 \mathrm{~min}$ at $94^{\circ} \mathrm{C}, 1 \mathrm{~min}$ at $55^{\circ} \mathrm{C}$, and $1 \mathrm{~min}$ at $72^{\circ} \mathrm{C}$; the final extension was $7 \mathrm{~min}$ at $72^{\circ} \mathrm{C}$. After amplification, $10 \mu \mathrm{l}$ of each reaction mixture were submitted to agarose gel electrophoresis analysis or enzymatic digestion.

\section{Eco57 I digestion}

A $10 \mu$ aliquot of the PCR reaction mixture was mixed with $2 \mu \mathrm{l}$ of buffer $(100 \mathrm{mmol} / 1$ Tris- $\mathrm{HCl}, \mathrm{pH} 7.5,100 \mathrm{mmol} / 1 \mathrm{MgCl}$ ), $1 \mu \mathrm{l}$ of $0.2 \mathrm{mmol} / 1 \mathrm{~S}$-adenosyl- $L$-methonine, $1 \mu \mathrm{l}$ of $2 \mathrm{~g} / \mathrm{l}$ bovine serum albumin, $5.5 \mu \mathrm{l}$ of distilled water and $0.5 \mu \mathrm{l}$ of Eco57 I ( 4 units/ $\mu$ l, Fermentas, Lithuania; distributed by New England Biolabs). The digestion was carried out at $37^{\circ} \mathrm{C}$ for $1 \mathrm{~h}$ and stopped by adding $1 \mu \mathrm{l}$ of $0.5 \mathrm{~mol} / \mathrm{l}$ EDTA. After digestion the fragments were separated on a $1.5 \%$ or $2 \%$ agarose gel and stained with ethidium bromide.

\section{Slot-blot-hybridization}

A $10 \mu$ l aliquot of the PCR reaction mixture was submitted to the slot-blot hybridization described by Enomoto et al. (10) on a Hybri-slot Manifold (BRL Life Technologies Inc., MD 20877, U.S.A.). After blotting, the duplicate nitrocellulose filters were treated in a Stratalinker UV Crosslinker (Stratagene, CA 92037, U.S.A.), then probed respectively with two allele-specific ${ }^{32} \mathrm{P}$ oligonucleotides, for $\mathrm{ALDH}_{2}^{1}$ and $\mathrm{ALDH}_{2}^{2}$, as described by $\mathrm{Hsu}$ et al. (8), using the prehybridization and hybridization conditions outlined by $\mathrm{Crabb}$ et al. (9). Each filter was exposed to Kodak XAR-5 film for several hours, with one intensifying screen.

\section{Results and Discussion}

Although the recognition sequence for Eco57 I is in Exon 12 where the Oriental point mutation occurs, the cutting point of the restriction enzyme is located 6 to 8 nucleotides downstream from the exon (fig. 1). In order to distinguish a digested PCR amplified fragment from an undigested one, it was necessary to amplify a PCR fragment at least 50 base pairs longer than Exon 12. Unfortunately, except for the first 10 bases, the sequence of intron 12 of the $\mathrm{ALDH}_{2}$ gene is not available. Thus it is not possible to design a primer that is fully complementary to the sequence of intron 12.

To solve this problem we designed a primer by extending a 41 base pair of GC-clamp at the $5^{\prime}$-end of a 19 mer oligonucleotide which is complementary to the exon 12-intron 12 known sequence of the $\mathrm{ALDH}_{2}$ gene (fig. 1). Using this primer (designated as Primer \#2) and the other primer (designated as Primer \#1, see fig. 1) a 176 base pair fragment was amplified from genomic DNA by the PCR and visualized with ethidium bromide on the agarose gel (fig. 2).

After digestion with Eco57 I, the 176 base pair fragment from 10 subjects (including 5 Orientals) were found to be cut into two segments (131 base pairs and 45 base pairs), while the fragment from subject 4 remained intact as one fragment and the fragment from subject 5 was partially (40\%) cut as shown in figure 3 (the 45 base pair bands overlap with the 60 pair primer \#2 bands).

These results show that sample 4 was from an individual who carries a homozygous atypical $\mathrm{ALDH}_{2}$ 

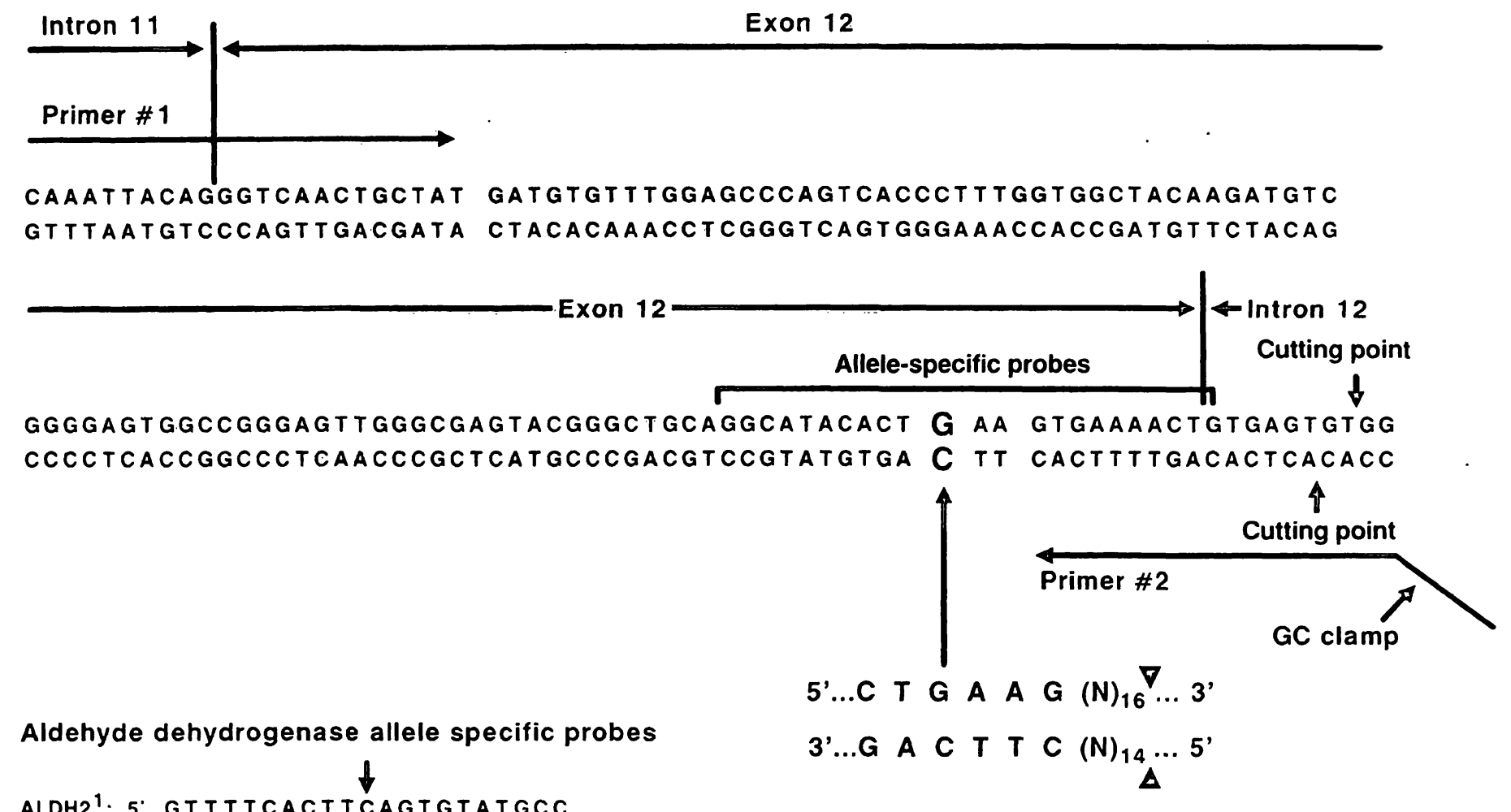

Eco57l recognition sequence

Fig. 1. Structure of the common $\mathrm{ALDH}_{2}$ gene in the region amplified by the polymerase chain reaction. Two oligonucleotides, primer \#1 and primer \#2, serve to initiate DNA synthesis of the 176 base pair fragment. The nucleotide bases in bold type indicate the position of the mutation in the atypical allele. The two allele-specific probes are those described by $H s u$ et al. (8) and by $\mathrm{Crabb}$ et al. (9). The site of the single base change in the oligonucleotide $\mathrm{ALDH}_{2}^{2}$ is indicated by an arrow. The oligonucleotides anneal to complementary DNA strands.
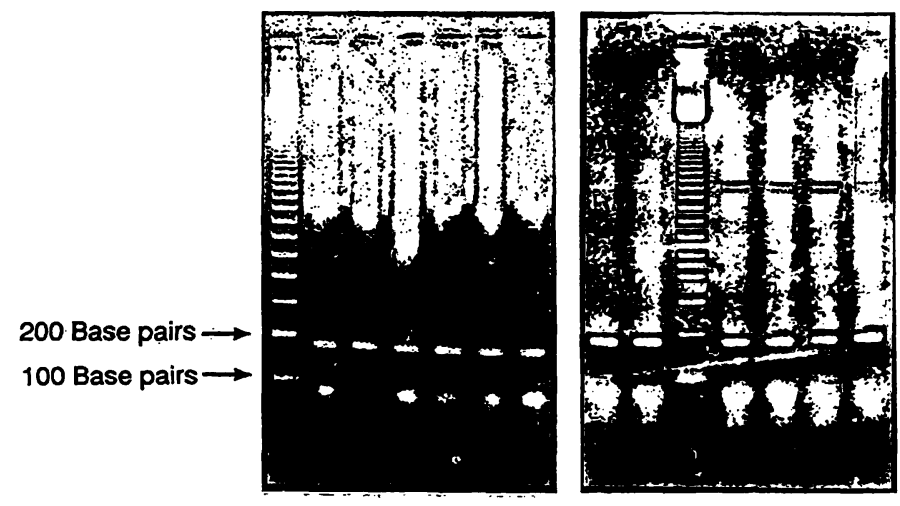

$L N_{1} N_{2} N_{3} N_{4} N_{5} N_{6} \quad N_{7} N_{8} L N_{9} N_{10} N_{11} N_{12}$

Fig. 2. The genomic DNA from whole blood or hair root samples was amplified, using the primers described in Materials and Methods, and subjected to electrophoresis in $2 \%$ agarose gel, followed by ethidium bromide staining. Lane $L$ is 100 base pair ladder. Lanes $N_{1-12}$ are samples from subjects $1-12$ (not digested with restriction enzyme). The major band generated corresponds to the 176 base pair product.

gene $\left(\mathrm{ASDH}_{2}^{2} / \mathrm{ALDH}_{2}^{2}\right)$, sample 5 from the individual who carries the heterozygous $\mathrm{ALDH}_{2}$ gene $\left(\mathrm{ALDH}_{2}^{1} /\right.$ $\mathrm{ALDH}_{2}^{2}$ ) and samples $1-3$ and 6-12 were taken from the individuals who carry the common homozygous $\mathrm{ALDH}_{2}$ gene $\left(\mathrm{ALDH}_{2}^{1} / \mathrm{ALDH}_{2}^{1}\right)$.
In order to confirm the new method, the PCR products were transferred to nitrocellulose by the slot-blot technique and the filters were hybridized with the two specific $\mathrm{ALDH}_{2}$ allele ${ }^{32} \mathrm{P}$-labelled probes. After washing, the filters were exposed to X-ray film. As shown in figure 4 the DNA amplified from sample 4 was only recognized by probe $\mathrm{ALDH}_{2}^{2}$, the DNA amplified from sample $1-3$ and 6-12 were only recognized with probe $\mathrm{ALDH}_{2}^{1}$, and the DNA amplified from sample 5 was recognized with both the probe for $\mathrm{ALDH}_{2}^{1}$ and the probe for $\mathrm{ALDH}_{2}^{2}$. The new method gives the same results as the Southern blot radioactive method $(5,8-11)$.

According to the Eco57 I manufacturer's information, the cleavage of DNA by this restriction enzyme is never quantitative. In addition to the 131 base pair band, all subjects (except 4 and 5) show a very weak undigested band at the location of the 176 base pair band on the agarose gel (fig. 3). This may be the reason for the fact that for sample 5 (heterozygote) about $40 \%$ of the 176 base pair fragment was found to be cut instead of $50 \%$. However, this characteristic of the enzyme does not affect the genotype of the samples. 

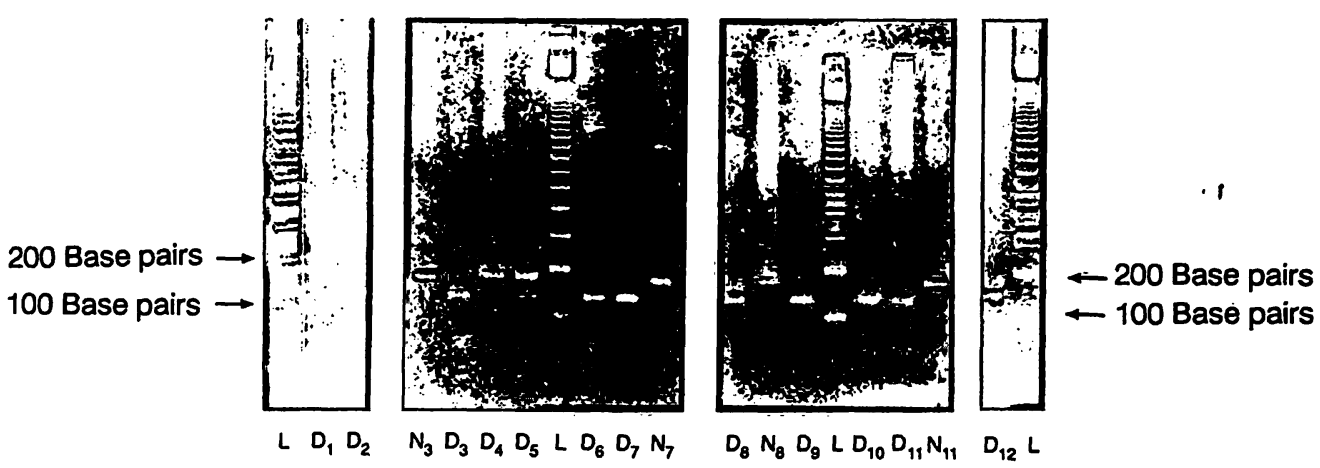

Fig. 3. The polymerase chain reaction (PCR) products were digested with restriction enzyme Eco57 I as described in Materials and Methods, subjected to electrophoresis in $2 \%$ agarose gel (or $1.5 \%$ on the extreme right), followed by ethidium bromide staining. Lane $\mathrm{L}$ is a 100 base pair ladder. $\mathrm{N}=$ non-digested PCR product, $\mathrm{D}=$ Eco57 I digested PCR product.

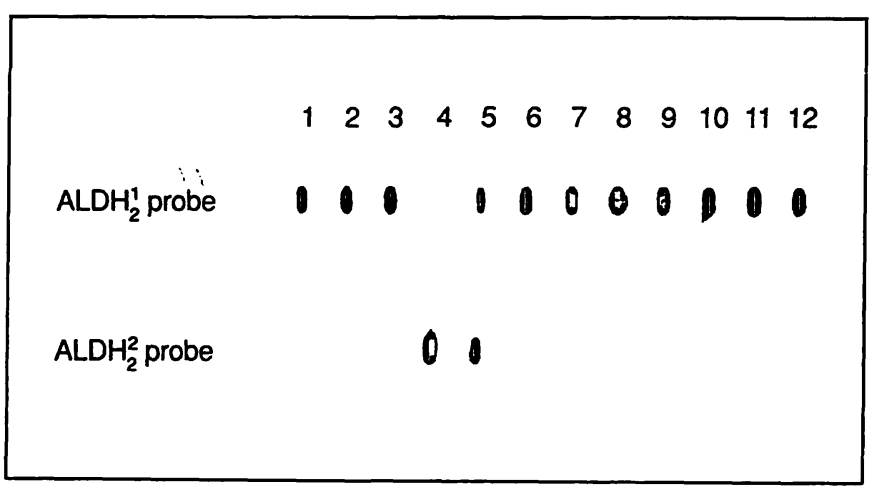

Fig. 4. The polymerase chain reaction (PCR) products were slot blotted on nitrocellulose filters as described by Enomoto et al. (10), hybridized with two ${ }^{32} \mathrm{P}$-labelled allele-specific probes, $\mathrm{ALDH}_{2}^{1}$ and $\mathrm{ALDH}_{2}^{2}$, described in figure 1 , followed by autoradiography.

\section{References}

1. Hsu, L. C., Tani, K., Fujiyoshi, T., Kurachi, K. \& Yoshida, A. (1985) Cloning of cDNA's for human aldehyde dehydrogenase 1 and 2. Proc. Natl. Acad. Sci. USA 82, $3771-$ 3775.

2. Mizoi, Y., Ijiri, I., Tatsuno, Y., Kijima, T., Fujiwara, S. \& Adachi, J. (1979) Relationship between facial flushing and blood acetaldehyde levels after alcohol intake. Pharmacol. Biochem. Behav. 10, 303-311.

3. Harada, S., Agarwal, D. P. \& Goedde, H. W. (1981) Aldehyde dehydrogenase deficiency as cause of facial flushing reaction to alcohol in the Japanese. Lancet $i i, 982$.

4. Shibuya, A. \& Yoshida, A. (1988) Frequency of the atypical aldehyde dehydrogenase-2 gene $\left(\mathrm{ALDH}_{2}^{2}\right)$ in Japanese and Caucasians. Am. J. Hum. Genet. 43, 741-743.

5. Singh, S., Fritze, G., Fang, B., Harada, S., Paik, Y. K., Eckey, R., Agarwal, D. P. \& Goedde, H. W. (1989) Inheritance of mitochondrial aldehyde dehydrogenase: Genotyping in Chinese, Japanese and South Korean families reveals dominance of the mutant allele. Hum. Genet. 83, 119121.

6. Harada, S., Agarwal, D. P. \& Goedde, H. W. (1985) Aldehyde dehydrogenase polymorphism and alcohol metabolism in alcoholics. Alcohol 2, 391-392.
In conclusion, we have developed a new approach for genotyping the common and the atypical aldehyde dehydrogenase $\left(\mathrm{ALDH}_{2}\right)$ alleles, which

(i) is considerably faster and simpler than presently available methods,

(ii) does not use a radioactive isotope and

(iii) requires very minute amounts of DNA, which can be obtained from a drop of whole blood or from hair roots.

This new approach should be of value in the genotyping of populations for epidemiological and genetic studies.

7. Thomasson, H. R., Edenberg, H. J., Crabb, D. W., Mai, X-L., Jerome, R. E., Li, T-K., Wang, S-P., Lin, Y-T., Lu, R-B. \& Yin, S-J. (1991) Alcohol and aldehyde dehydrogenase genotypes and alcoholism in Chinese men. Am. J. Hum. Genet. 48, 667-681.

8. Hsu, L. C., Bendel, R. E. \& Yoshida, A. (1987) Direct detection of usual and atypical alleles on the human aldehyde dehydrogenase-2 $\left(\mathrm{ALDH}_{2}\right)$ locus. Am. J. Hum. Genet. 41, 996-1001.

9. Crabb, D. W., Edenberg, H. J., Bosron, W. F. \& Li, T-K. (1989) Genotypes for aldehyde dehydrogenase deficiency and alcohol sensitivity. The inactive $\mathrm{ALDH}_{2}^{2}$ allele is dominant. J. Clin. Invest. 83, 314-316.

10. Enomoto, N., Takase, S., Takada, N. \& Takada, A. (1990) Alcoholic liver disease in heterozygotes of mutant and normal aldehyde dehydrogenase-2 genes. Hepatol. 13, $1071-1075$.

11. O'Dowd, B. F., Rothhammer, F. \& Israel, Y. (1990) Genotyping of mitochondrial aldehyde dehydrogenase locus of native American Indians. Alcoholism: Clin. Exp. Res. 14, $531-533$.

Dr. Yedy Israel

Primary Mechanisms Department

Addiction Research Foundation

33 Russell Street :

Toronto, Ontario M5S 2S1

Canada 